\title{
FONÉTICA E FONOLOGIA PORTUGUESAS: UM MODELO DIDÁTICO LABORATORIAL
}

\section{PORTUGUESE PHONETICS AND PHONOLOGIE: A TEACHING LABORATORIAL MODEL}

\author{
Vicente Masip* \\ Universidade Federal de Pernambuco, Recife, PE, Brasil
}

Resumo: As línguas naturais são veículos orais de comunicação que eventualmente se escrevem. É muito importante refletir sobre os sons do português, usando todos recursos que a tecnologia coloca ao nosso dispor, especialmente os laboratórios fonéticos, que nos permitem gravar mensagens, analisá-las, diagnosticá-las e transmiti-las. Propomos um modelo, em duas fases, a primeira mais simples e a segunda mais elaborada, que poderá ser usado como suporte para o ensino da língua portuguesa a nativos e a estrangeiros e, especialmente, como instrumento de pesquisa capaz de detalhar o registro dos sons, seus traços segmentais e prosódicos; a partir da investigação sonora que sugerimos, será possivivel estabelecer contrastes, identificar convergências e divergências e esclarecer ambiguidades e equívocos, procedimentos especialmente úteis para professores do ensino fundamental, que carecem de instrumentos para fazer a ponte entre a fala e a escrita, carência que se reflete na pobreza de resultados obtidos na alfabetização de crianças, jovens e adultos brasileiros. A pesquisa do som, que até alguns anos atrás constituía uma atividade complexa e onerosa, foi progressivamente simplificada e barateada até se tornar uma ferramenta ao alcance de todos.

Palavras-chave: fonética; fonologia; laboratório; pesquisa; modelo.

\begin{abstract}
Natural languages are oral communication vehicles that eventually are written. It is very important to reflect on the sounds of the Portuguese language, using all the available resources that technology offer to us, especially the phonetic laboratories that allow us to record messages, analyze, diagnose and transmit them. We propose a model in two stages: the first, simpler, and the second more elaborated, which could be used as a support for teaching Portuguese language to native speakers; and the foreign, especially, as a research tool capable of representing the recording of sounds, its segmental and prosodic features. From the sound research we have suggested, it's possible to establish contrasts, identify convergences, divergences, clarify ambiguities and misunderstandings, useful procedures for elementary school teachers, which lack the tools to link the speaking and writing, that reflects poor results in literacy of Brazilians'children, youth and adults. The research of sound, was an complex and expensive activity some years ago, however it has gradually become simplified and cheaper until it turns an available tool to everyone.
\end{abstract}

Keywords: Phonetics; Phonology; Laboratory; Research; Model.

* Professor doutor do Departamento de Letras da Universidade Federal de Pernambuco UFPE, Recife, PE, Brasil; vmv47@terra.com.br 
Linha D'Água (Online), São Paulo, v. 28, n. 1, p. 173-192, jun. 2015

\section{Introdução}

Os seres humanos estabelecem relações muito complexas uns com os outros por meio de gestos, posturas, olhares, sons, contato físico, olfato. Alguns sons que emitimos e escutamos formam um código, chamado língua, mediante o qual nos entendemos, porque distinguimos perfeitamente cada um dos signos desse código e seu significado (Cf. SAUSSURE, 1989).

As línguas naturais são veículos orais de comunicação; algumas delas se transcrevem. Mesmo que não possuamos estatísticas precisas sobre o percentual de línguas e variantes dialectais ágrafas existentes no mundo, uma observação superficial nos permite afirmar que facilmente pode chegar a noventa por cento. Basta considerar a realidade brasileira: apenas o português e o tupi possuem sistemas ortográficos consolidados; em compensação, quantas línguas indígenas ágrafas existem no país? A Revista Lingua Portuguesa (n. 26, p. 57, 2010) afirma que existem no Brasil 180 línguas indígenas, faladas por 225 etnias (110 em extinção por terem menos de 500 falantes), provenientes de famílias, a partir de troncos como o macro-tupi, o macro-jê e o timbira. Algumas dessas, porém, ainda não foram classificadas e se consideram isoladas. Realidade semelhante encontra-se na África, Índia, China, Austrália, Nova Zelândia.

Dado que as línguas naturais são preponderantemente veículos orais de comunicação, é preciso aceitar que o estudo dos sons de um idioma ou variante dialectal é de fundamental importância, especialmente quando um falante nativo se dispõe a ensinar o próprio idioma ou a aprender uma língua segunda. Acontece que os estudos acadêmicos de fonologia e fonética vêm sendo preteridos ao longo das últimas décadas no país inteiro. Assim, o brasileiro que decide dedicar-se ao ensino de português tem uma grande dificuldade para transmitir o conteúdo segmental e prosódico da língua, base da escrita, pois ignora a organização interna do seu sistema sonoro (MASIP, 2014, p. 2-3).

\section{Definições}

Ferdinand de Saussure (1857-1913), no Curso de Linguística Geral, propõe uma nova ciência, a semiologia, cujo objeto é o estudo de todos os modos de comunicação existentes no seio da vida social, transmitidos por meio de sinais, que são convenções abertas, isto é, passíveis de interpretações diversas. O ser humano se comunica mediante gestos, olhares, posturas, modo de andar, modo de sentar-se, residência, meio de transporte, roupa, adereços, joias, sapatos, óculos, relógios, tanto na família quanto no bairro, na escola, no escritório e na rua. A ciência criada pelo linguista francês é tão importante que, a partir de meados do século XX, todos 
Linha D'Água (Online), São Paulo, v. 28, n. 1, p. 173-192, jun. 2015

os cursos de medicina introduziram a disciplina semiologia para auxiliar futuros doutores no diagnóstico de doenças mediante a interpretação dos sinais que os pacientes emitem: cor da pele, vivacidade do olhar, tremores, calafrios, inchaço, rigidez de membros, tensão muscular, protuberâncias ósseas.

A semiótica é a parte da semiologia que estuda a comunicação por signos, que são convenções fechadas, isto é, passíveis de interpretações precisas, porque seu número é limitado e organizado hierarquicamente. Charles Morris (19011999) foi o primeiro pensador a usar o termo, em 1938, na obra Fundamentos da teoria dos signos.

O signo linguístico é, portanto, uma convenção fechada que consta de significante, ou imagem acústica (som), e significado ou conteúdo cognitivo conceitual. O significante da palavra /'meza/ mesa, por exemplo, compõe-se de quatro sons: $[\mathrm{m}][\mathrm{e}][\mathrm{z}][\mathrm{a}]$; e seu significado é "substância corpórea inanimada, móvel para usos diversos".

O significante do código linguístico consta, por sua vez, de substância, que é o som tal como percebido pelo ouvido, estudado pela fonética, e de forma, que é a organização dessa substância, estudado pela fonologia. Para simplificar, estabelecendo um paralelismo com a música, podemos afirmar que a fonética estuda a melodia da fala, enquanto que a fonologia elabora a partitura dessa melodia; em outras palavras, fonética tem a ver com som e fonologia, com teoria do som.

Oposição distintiva: mecanismo, fônico e ortográfico, que permite distinguir, por contraste, o significado das palavras: /'matu//'patu//'fatu/ /'gatu/ mato, pato, fato, gato, por exemplo, designam entidades diversas; só distinguimos seu significado pela oposição entre o primeiro som, ou letra, de cada uma delas.

Traço distintivo fonológico: cada uma das dimensões teóricas de um fonema: /p/, por exemplo, sob uma ótica articulatória, é um fonema oclusivo, bilabial, surdo; possui, portanto, os traços de oclusividade, bilabiaridade e surdez.

Fonema: mínima unidade fonológica distintiva ou conjunto de traços distintivos: /p/, /i/, /b/.

Alofone ou som: variante ou realização concreta de um fonema. $\mathrm{O}$ fonema /i/, por exemplo, realiza-se mediante os alofones [i] fechado, [j] semivogale [î] nasalizado.

Vogal: núcleo silábico: /a/; emissão: (sem obstáculos) [a].

Consoante: margem silábica /b/; articulação (com obstáculos) [b].

Arquifonema: conjunto de traços distintivos comuns a dois ou mais fonemas. Transcreve fonologicamente várias consoantes, situadas em posição pós-vocálica, que perdem algum traço distintivo e, consequentemente, seu modo unívoco de articular-se, ou seja, podem pronunciar-se de várias formas. O português possui 
Linha D'Água (Online), São Paulo, v. 28, n. 1, p. 173-192, jun. 2015

quatro arquifonemas: /N/ /'kaNtu/ /'kaNpu/ (canto, campo) /R/ /'kaRta/ (carta), /S/ /'gaS/ (gás), /L/ /'maL) (mal).

Semivogal: margem silábica anterior ou posterior ao núcleo; emissão: [w] ['kwa1], ['kaw:za] (qual, causa).

Sílaba: núcleo ou conjunto de núcleo e margem ou margens: /'kaRni/; emissão ou conjunto de emissão e articulação/articulações ['kaR:ni] (car-ne).

Palavra fônica: conjunto unitário de fonemas: /mi 'Jamu 'kaRmu \III/ (Me chamo Carmo).

Prosodema: parâmetro prosódico distintivo de tom, intensidade ou duração.

Acento paradigmático: o último acento de uma palavra fônica: /mi 'Samu 'kâRmu \III/

Grupo fônico: conjunto de palavras fônicas: /mi 'Samu 'kaRmu $\rightarrow$ i eS'tóu a'kí \|ll/ (Me chamo Carmo e estou aqui).

Acento sintagmático: o último acento de um grupo fônico: /mi 'Samu 'kạ $\mathrm{R}>\mathrm{mu} \rightarrow \mid \mathrm{i}$ eS'tou a'ki $\backslash\|\| / /$ (TROUBETZKOY,1976, p. 30-99; MARTINET, 1978, p. 88-89).

\section{As três grandes escolas fonológico/fonéticas}

Além da abordagem articulatória já citada, Jakobson, o linguista russo que editou uma autobiografia de Trubetzkoy, organizou, junto com Morris Halle, pesquisador letão que fez carreira nos EUA, 12 pares de traços, 3 prosódicos e 9 inerentes (segmentais), sobre a dimensão física do som, dando origem à fonética acústica. Eis uma síntese, que poderá servir de bússola para professores, tutores, monitores e pessoas autodidatas em geral:

» o que determina que alguns sons portugueses sejam vocálicos ([i e $\varepsilon$ a $\rho$ o u $1 \kappa \mathrm{r}$ R]) é o fato de serem emitidos sem obstáculos, o que se reflete acusticamente numa estrutura formântica definida (traço inerente);

» o que determina que alguns sons portugueses sejam consonantais ( $[\mathrm{p} \mathrm{b} \mathrm{t}$ d kg fv s z $3 \mathrm{~m} \mathrm{n} \mathrm{n} 1 \kappa \mathrm{r}$ ] ) é o fato de serem emitidos com obstáculos, o que se reflete acusticamente em áreas de não ressonância no espectrograma, isto é, na presença de espaços em branco (traço inerente). Os sons $1 K \mathrm{r}$ R são vocálicos e consonantais ao mesmo tempo porque possuem uma estrutura formântica definida, mas se produzem mediante obstáculos, mesmo insignificantes, provenientes do contato da língua com os alvéolos. 
» são agudos os sons produzidos mediante a divisão da cavidade bucal pela língua ( $\left[\right.$ i e $\varepsilon$ t d s z $\left.\int 3 n \mathrm{n} 1 K \mathrm{r}\right]$ ), o que se reflete acusticamente no seu registro na parte alta do espectro; são graves os sons não produzidos mediante a divisão da cavidade bucal pela língua ([a $\rho$ o u p b k g f v m R]), o que se reflete acusticamente no seu registro na parte baixa do espectro (traço prosódico);

» são densos os sons produzidos mediante uma configuração especial do ressonador anterior, isto é, da parte que fica entre o ápice da língua e a arcada dental inferior ([ $\varepsilon$ a $\circ \mathrm{k} \mathrm{g} \mathrm{s} \mathrm{z} 3 \mathrm{n} K])$, o que se reflete numa concentração elevada de energia (manchas mais escuras) em uma zona; são difusos ([i e o u p b t d f v m n l r R]) os sons que não são produzidos mediante a configuração especial apontada, o que se reflete numa débil concentração de energia, decorrente de manchas menos escuras (traço inerente);

» são estridentes os sons que produzem ruído devido ao atrito entre a corrente de ar e o esmalte dentário ([s $\left.\int\right]$ ), o que se reflete na total irre-

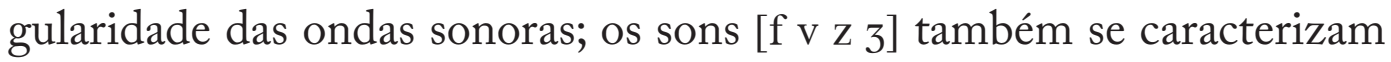
por certa irregularidade das ondas; são doces os demais ([p b t d k g m n n $1 \kappa \mathrm{r}$ ]) porque não se articulam de modo ruidoso nem produzem ondas irregulares; este traço não se aplica às vogais (traço inerente);

" são considerados interruptos os sons que se produzem mediante o fechamento do aparelho fonador ( $[\mathrm{p} \mathrm{b} \mathrm{t} \mathrm{d} \mathrm{k} \mathrm{g} \mathrm{r]} \mathrm{),} \mathrm{o} \mathrm{que} \mathrm{se} \mathrm{reflete} \mathrm{acustica-}$ mente em momentos de silêncio, caracterizados por espaços em branco ao longo de toda a articulação; são contínuos os demais ([i e $\varepsilon$ a $\supset$ o u f v s z $\left.\int 3 \mathrm{~m} \mathrm{n} 11 K \mathrm{R}\right]$ ) porque não se produzem mediante fechamento do aparelho fonador, nem mostram momentos de total silêncio no espectrograma (traço inerente). $\mathrm{O}$ som $[\mathrm{r}]$ é considerado interrupto porque, no momento em que se dá o contato entre o ápice da língua e o palato, aparece no espectrograma uma fístula de silêncio;

» são considerados nasais os sons [ $\mathrm{m} \mathrm{n} \mathrm{n}$ ], porque apresentam zonas de formantes em determinadas frequências e provocam a redução de intensidade no primeiro formante dos sons vocálicos contíguos; são orais os demais ( $\left[\mathrm{i}\right.$ e $\varepsilon$ a $\supset$ o u p b t d k g f v s z $\left.\int 31 K \mathrm{r}\right]$ ) porque não apresentam zonas de formantes em determinadas frequências, nem provocam a redução de intensidade no primeiro formante dos sons vocálicos contíguos (traço inerente). Consequência importante: os sons vocálicos são sempre orais, sofrendo nasalização, em algumas ocasiões, pela contiguidade de [m n n];

" são considerados sonoros os sons que se produzem mediante a vibração das cordas vocais ([i e $\varepsilon$ a $\rho$ o u b d g v z $3 \mathrm{~m} \mathrm{n} 1 \kappa \mathrm{r}]$ ), o que se reflete 
Linha D'Água (Online), São Paulo, v. 28, n. 1, p. 173-192, jun. 2015

na presença de formantes no espectro; são considerados surdos os sons que não se produzem mediante a vibração das cordas vocais ([p t k f s $\left.\int\right]$ ), o que se reflete na ausência de formantes no espectro (traço inerente). Jakobson e Halle elencam, na obra citada, mais quatro traços que não se aplicam ao português: bemolizado (traço prosódico), presente em algu-

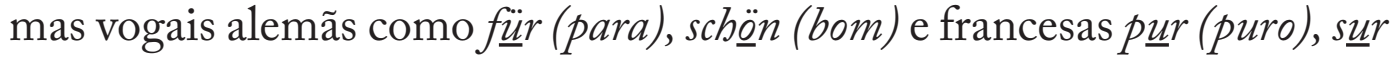

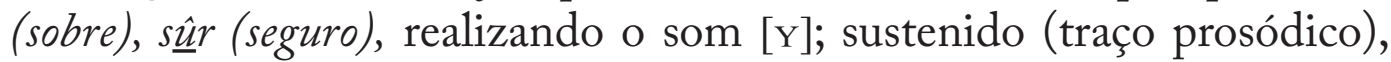
presente no som [ь] inglês de for (para), chair (cadeira); brusco (traço inerente), característico de alguns cliques ['] do hotentote (ou bosquímano, língua falada por pequenos grupos étnicos do sudeste da África) e dos sons hebraicos e árabes álef/álif [?] e áiin [ [ ] e tenso (traço inerente), presente nos sons ingleses $\left[\mathrm{p}^{\mathrm{h}} \mathrm{t}^{\mathrm{h}} \mathrm{k}^{\mathrm{h}}\right]$ de poor (pobre), talk (conversa), coat (casaco) (JAKOBSON/HALLE, 1980, p. 31-49).

Noam Chomsky, auxiliado pelo mesmo Halle, formulou um novo sistema de análise do som, muito minucioso, de índole articulatória, que seria conhecido como fonologia gerativa, abordagem que, por sua vez, originou uma grande diversidade de enfoques teóricos.

Convém acrescentar que as três escolas se completam, enriquecendo-se mutuamente. Há divergências mínimas entre elas, talvez a mais importante seja a concepção de sonoridade/surdez; para Jakobson, os sons sonoros se produzem mediante a vibração das cordas vocais e os surdos, sem vibração; para Chomsky, as cordas vocais vibram sempre, de modo tenso nos sons sonoros e de modo relaxado nos surdos (Cf. CHOMSKY/HALLE, 1968).

\section{Um modelo didático sonoro da língua portuguesa em duas fases}

Propomos, neste artigo, um modelo didático sonoro da língua portuguesa, tanto para alunos nativos quanto estrangeiros, a partir da fonética acústica de Jakobson/Halle, mediante os laboratórios fonéticos Audacity e Praat, de uso público, disponíveis na internet. Tomamos como referência os traços distintivos propostos por ambos os autores (JAKOBSON/HALLE, 1980, p. 31-49), que aplicamos ao português.

\section{Detalhamento da primeira fase}

Inicialmente recomendamos o uso do laboratório de som Audacity, disponível para instalação na internet ao digitar a palavra chave; atualmente (maio de 2015) convém usar a versão 2.0.6. A imagem 1 mostra o recurso quando é aberto: 
Linha D'Água (Online), São Paulo, v. 28, n. 1, p. 173-192, jun. 2015

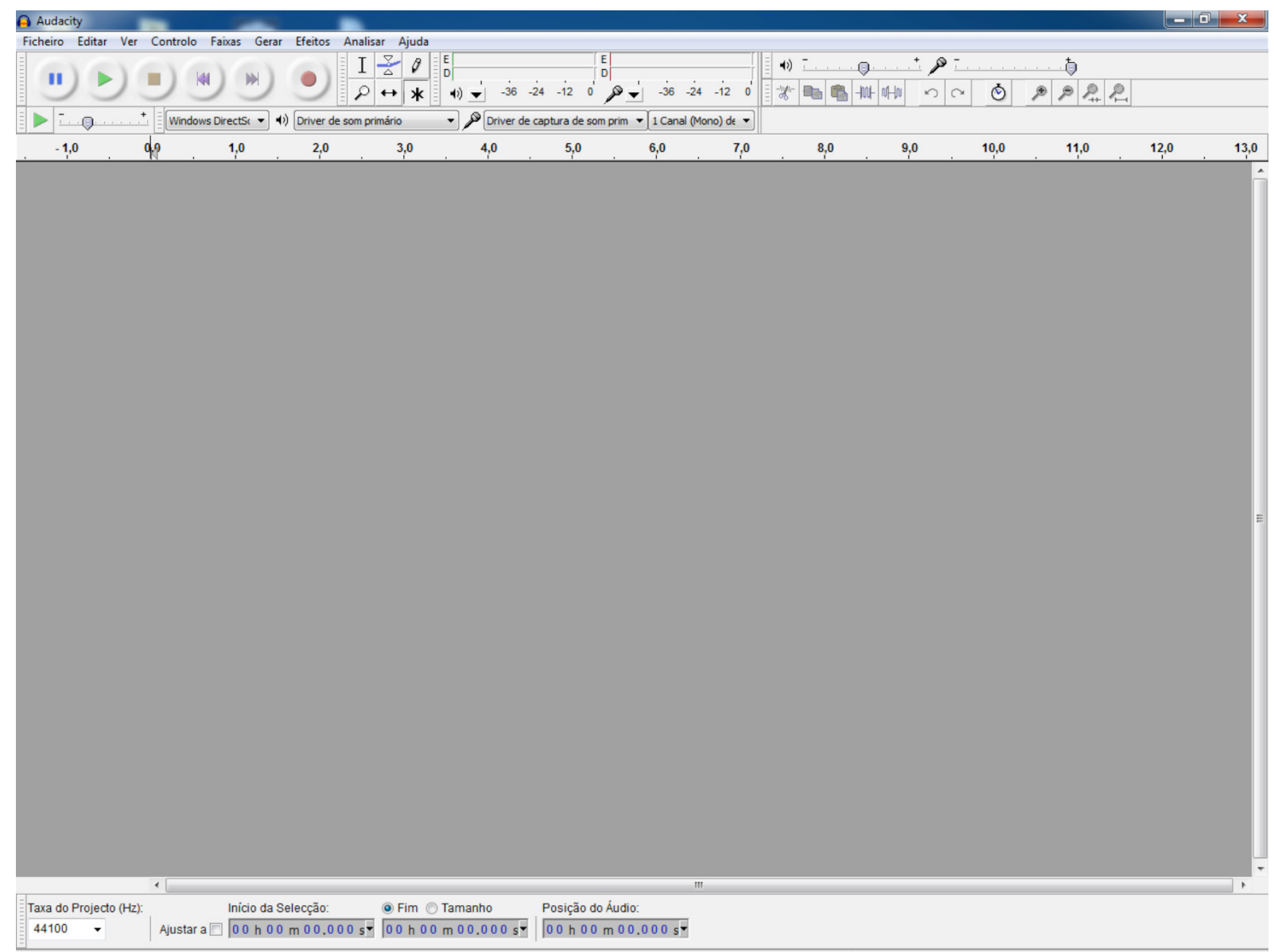

(2) C 9 o

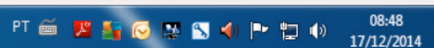

Imagem 1

Todas as funções podem ser consultadas no manual que aparece no momento do acesso. Para efetuar a gravação, poderá ser usado o microfone embutido que a maioria dos notebooks possui; ou, então, um externo, de preferência unidirecional. Os computadores mais modernos carecem de entrada para microfone; será necessário usar uma das portas USB, por onde se podem introduzir registros feitos com gravadores digitais ou, até, mediante telefones celulares; neste último caso, aconselha-se usar MP3, para evitar incompatibilidades, mediante o aplicativo audio-recorder, também disponível na internet. Quando uma gravação é de boa qualidade, a linha que aparece unindo os oscilogramas ${ }^{1}$ é reta e limpa; caso isso não aconteça, por causa de ruídos ou interferências, poderá ser usado o recurso remoção de ruído, clicando em efeitos.

1 Representação visual dos parâmetros de tempo (abscissa: linha horizontal) e da amplitude da onda (ordenada: linha vertical). 
Linha D'Água (Online), São Paulo, v. 28, n. 1, p. 173-192, jun. 2015

A imagem 2 mostra o oscilograma do enunciado Os vizinhos jogam peteca lá fora, na bodega de Mané, até sairem bolhas roxas, gravado no Audacity, que contém a totalidade dos fonemas ${ }^{2}$ portugueses ${ }^{3}$, realizados mediante sons segmentais ${ }^{4}$ vocálicos e consonantais; além do mais, apresenta oscilações de tom ${ }^{5}$, de intensidade ${ }^{6}$ e pausas. A gravação poderá ir acompanhada da transcrição fonológica ${ }^{7}$, fonética ${ }^{8}$ ou ortográfica, que se introduz clicando em faixas e em adicionar título à seleção; neste caso, optamos pela terceira, dado que, ao iníciar o estudo, o aluno desconhece a simbologia fonética. Note-se que a gravação foi feita usando a frequência ${ }^{9}$ de 22050, seguindo orientações de especialistas (MONTES DE OCA, 2011, p. 42). A vantagem do Audacity é que pode gravar enunciados de longa duração.

2 Mínima unidade fonológica distintiva ou conjunto de traços distintivos.

3 A língua portuguesa possui 7 fonemas vocálicos, todos orais: /i/ alto, anterior, palatal; /e/ médio/alto, anterior, palatal; / $\varepsilon /$ médio/baixo, anterior, palatal; /a/ baixo, central, vela; / o / médio/baixo, posterior, velar; /o/ médio/alto, posterior, velar e /u/alto, posterior, velar, além de 19 fonemas consonantais: /p/ oclusivo, bilabial, surdo; /b/ oclusivo, bilabial, sonoro; /t/ oclusivo, linguodental, surdo; /d/ oclusivo, linguodental, sonoro; /k/ oclusivo, velar, surdo; /g/ oclusivo, velar, sonoro; /f/ fricativo, labiodental, surdo; /v/ fricativo, labiodental, sonoro; /s/ fricativo, alveolar, surdo; /z/ fricativo, alveolar, sonoro; /S/ fricativo, palatal, surdo; /3/ fricativo, palatal, sonoro; /m/ nasal, bilabial, sonoro; /n/ nasal, alveolar, sonoro; /n/ nasal, palatal, sonoro; /1/ lateral, alveolar, sonoro; $/ K /$ lateral, palatal, sonoro; $/ \mathrm{r} /$ vibrante, alveolar, sonoro e /R/ vibrante, velar, sonoro (Cf. MATTOSO, 1977; CUNHA/CINTRA, 1985).

4 Divisíveis.

5 Chama-se também entonação: conjunto de variações de frequência fundamental (primeira onda sinusoidal periódica) que cumprem uma função linguística ao longo da emissão da voz.

6 Força. Mede-se em decibéis. Parâmetro originado diretamente pela pressão infraglótica (procedente dos pulmões, via traqueia).

7 Registro do perfil teórico sonoro de uma língua natural. Cada língua natural detém uma única fonologia.

8 Registro do perfil sonoro efetivamente realizado por um falante de determinada variante linguística. As línguas naturais detêm diversas realizações fonéticas.

9 Parámetro físico para medir o número de oscilações de uma onda. 
Linha D'Água (Online), São Paulo, v. 28, n. 1, p. 173-192, jun. 2015

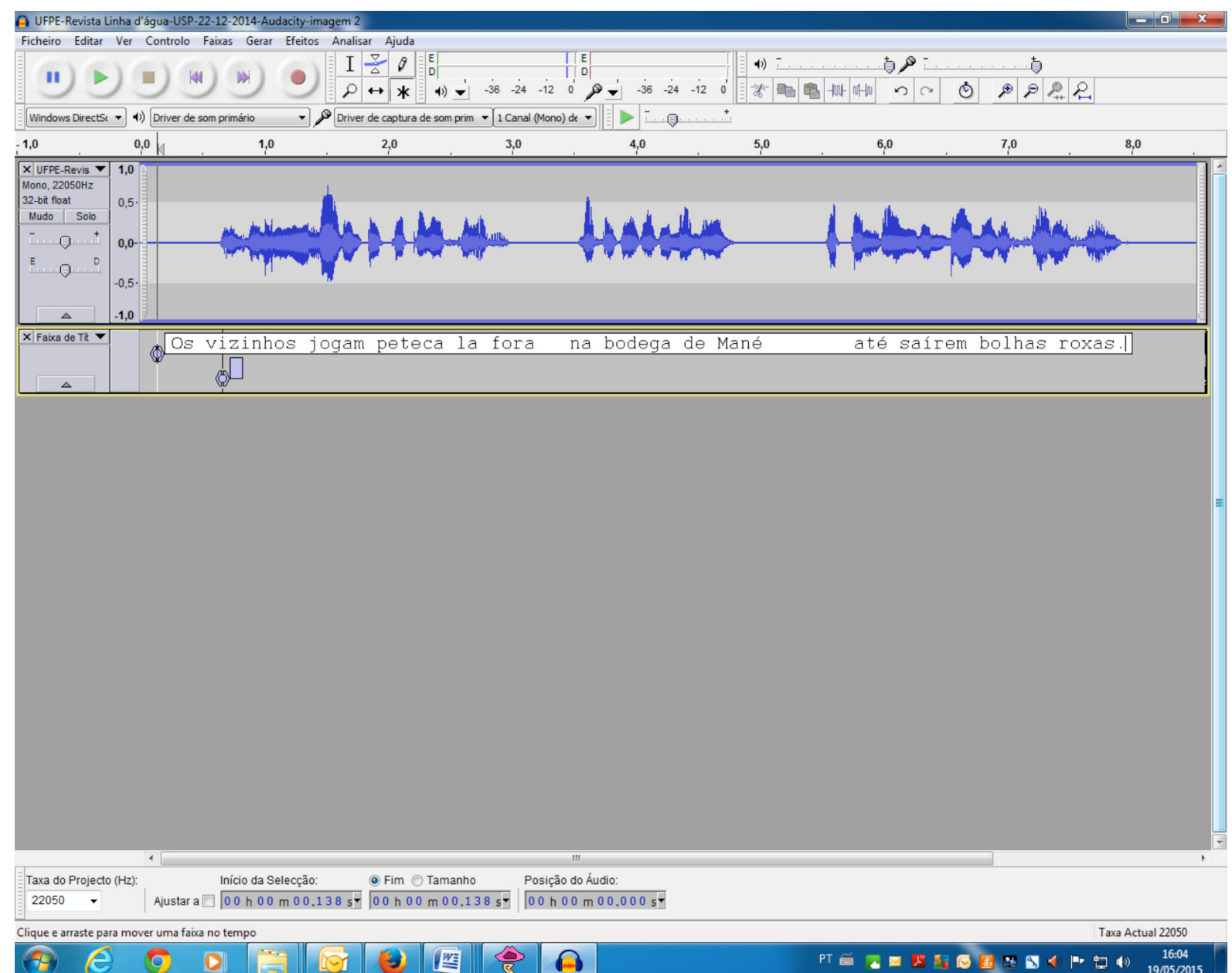

Imagem 2

Transcrição fonológica:

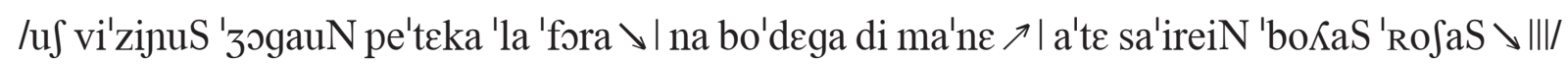

Transcrição fonética (variante ${ }^{10}$ portuguesa, produzida por um estrangeiro, residente há muitos anos no Recife, Brasil):

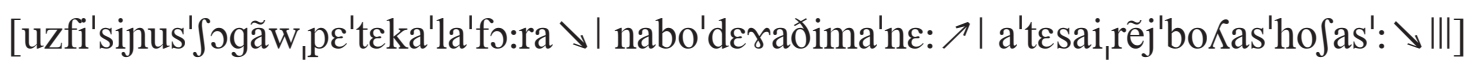

Quando estudarmos com detalhe a índole fonética desse enunciado, na segunda fase, apontaremos os desvios detectados.

10 Perfil fonético de uma língua natural em determinada região.

MASIP, V. Fonética e fonologia portuguesas... 
Etapas da primeira fase:

1) o professor grava o enunciado, mediante o laboratório Audacity, clicando no botão vermelho para iniciar, no símbolo quadrado para terminar e na seta verde para ouvir;

2) o professor arquiva a gravação, acessando ficheiro e escolhendo exportar,

3) o professor envia a gravação, anexada a um e-mail, para um receptor, que pode ser um estudante brasileiro de português, interessado em aprofundar os sons da língua, ou um estrangeiro, preocupado por melhorar a emissão e articulação de determinados sons;

4) o receptor ouve a gravação, a reproduz e devolve o arquivo ao professor;

5) o professor ouve a gravação do receptor, faz as observações pertinentes e convida o receptor a reproduzir novamente o enunciado, uma vez assimiladas as observações.

O processo poderá se prolongar, segundo os objetivos e metas pretendidos. Podemos dizer que a primeira fase se propõe a abordar os problemas de emissão ${ }^{11}$ e articulação ${ }^{12}$ dos receptores de modo intuitivo; o professor escuta a produção sonora de cada aluno e o orienta com o objetivo de superar as dificuldades encontradas; mas poderá acontecer que simples dicas não resolvam problemas segmentais ${ }^{13}$ ou prosódicos ${ }^{14}$, sendo necessário aprofundar o estudo.

\section{Detalhamento da segunda fase}

Para o aprofundamento recomendado, será necessário usar ferramentas de maior precisão. Convirá instalar no computador o laboratório Praat: doing phonetics by computer, disponível na internet e gratuito, como o anterior, digitando a palavrachave e fazendo o download da opção que convier; aconselhamos a 32-bit edition: praat5402 win32.zip (26 November 2014; 5.4 MB), por ser a mais universal.

O laboratório PRAAT, uma vez instalado, aparece na tela do computador como indica a imagem 3:

11 Produção vocálica; as vogais se emitem.

12 Produção consonantal; as consoantes se articulam.

13 Divisíveis, procedentes da emissão vocálica ou da articulação consonantal.

14 Não divisíveis ou suprassegmentais, característicos da entonação, intensidade e duração. 
Linha D'Água (Online), São Paulo, v. 28, n. 1, p. 173-192, jun. 2015

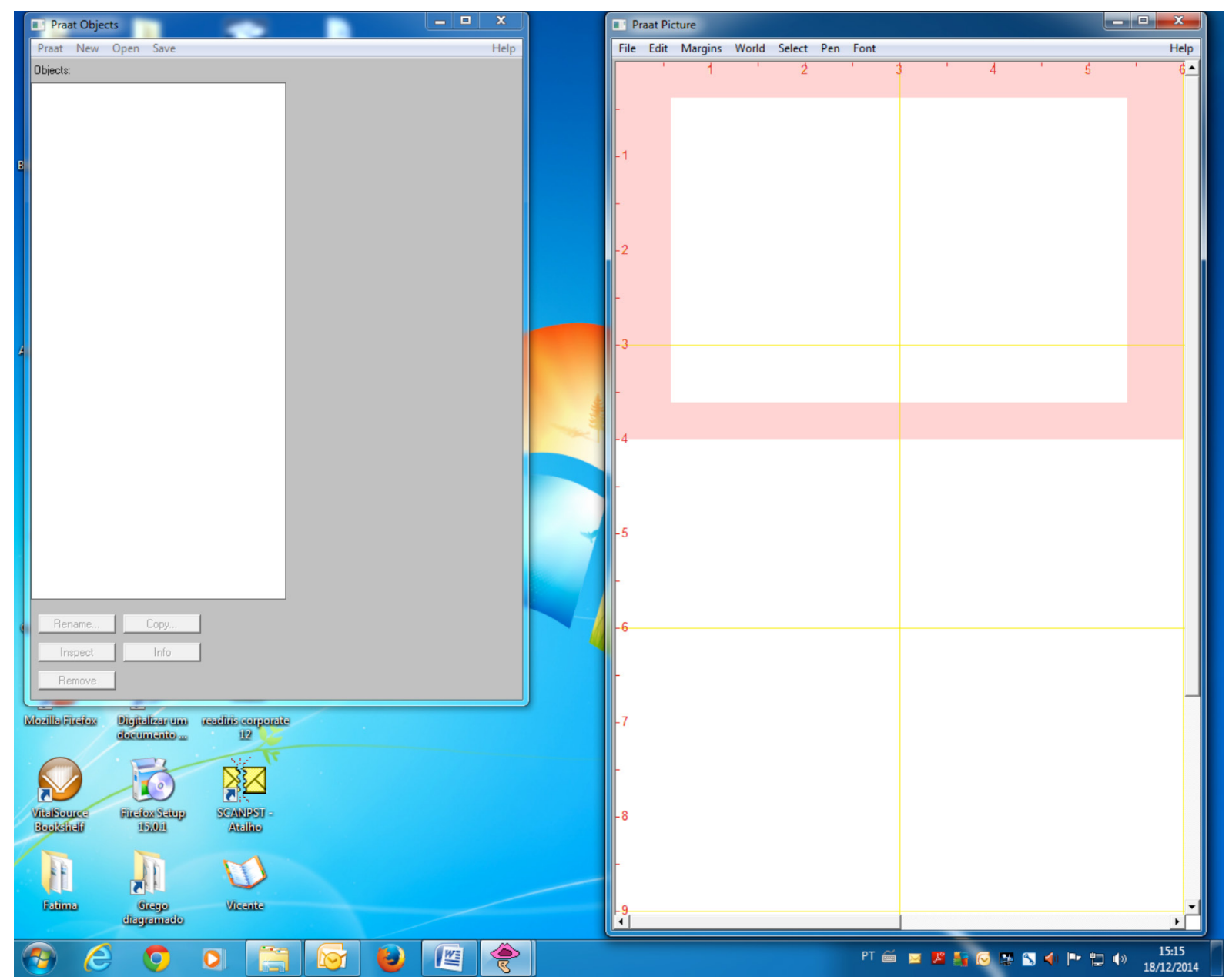

Imagem 3

Para gravar, escolha a tela Praat $\mid$ Objects, clique em new e, logo a seguir, em record mono sound ou record stereo sound. Abrirá uma janela; clique em record, grave o enunciado e, ao terminar, clique em stop e em save to list $\mathcal{E}^{2}$ close; se você tiver registrado a fala com um gravador ou com um telefone celular, clique em open e em read from file para importar a fala. O problema é que o PRAAT só consegue registrar enunciados de até 10 segundos; para compensar a limitação, pode-se usar o Audacity para gravar falas de qualquer comprimento, selecionando os trechos curtos que exijam um estudo mais aprofundado e enviando-os ao PRAAT do seguinte modo: pinta-se o trecho desejado e clica-se em ficheiro e exportar seleção; gerado o arquivo, bastará nomeá-lo e abri-lo quando necessário.

Gravamos, a seguir, no Praat, o mesmo enunciado do Audacity: Os vizinhos jogam peteca lá fora, na bodega de Mané, até saírem bolhas roxas; com o arquivo já pronto e registrado no Objects, clicamos em Annotate, logo a seguir, em To Textgride, substituindo as palavras Mary John bell por trans/fonol; o sistema gera um 
Linha D'Água (Online), São Paulo, v. 28, n. 1, p. 173-192, jun. 2015

novo arquivo; pintamo-lo junto com o original e clicamos em ViewEEEdit para visualizá-lo; usamos o zoom (escolhendo zoom to selection); na imagem 4, aparecem o oscilograma (em cima) e o espectrograma ${ }^{15}$ (embaixo) do enunciado, com o registro do tom em azul e da intensidade em amarelo; os formantes ${ }^{16}$ vocálicos aparecem destacados com pontinhos vermelhos; na faixa inferior, acrescentamos a transcrição fonológica do enunciado, cuja transcrição fonética desdobraremos progressivamente em três espectrogramas.

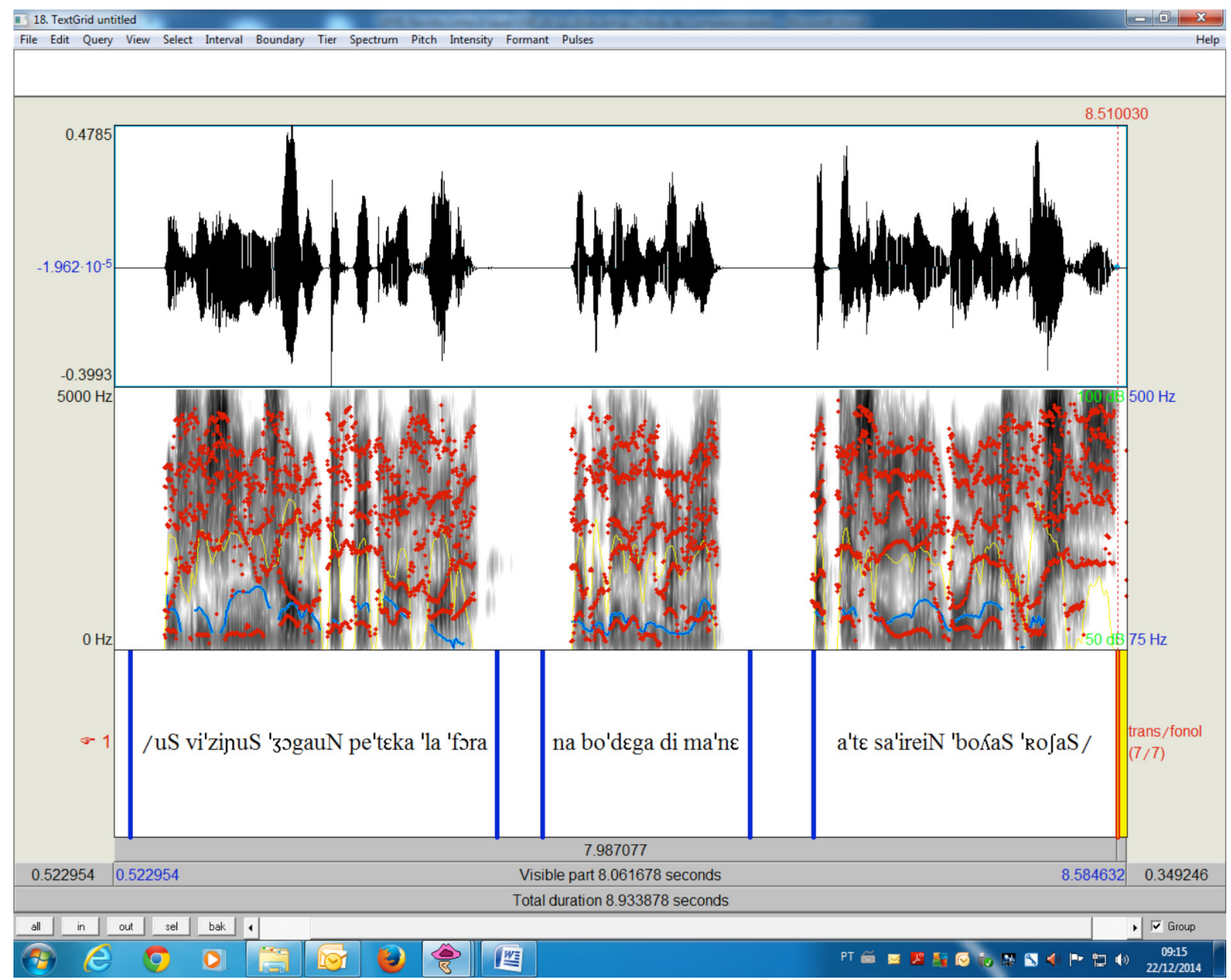

Imagem 4

15 Sucessão de espectros (conjuntos de sons parciais, ordenados a partir da frequência fundamental; imagem estática que mostra os harmônicos, sua altura frequencial e seu valor relativo dentro da estrutura formântica): mostra o conjunto de harmônicos (quaisquer componentes sinusoidais de uma onda periódica cuja frequência seja múltiplo inteiro da frequência do fundamental) na sua evolução temporal, sua altura frequencial e sua altura relativa mediante a intensidade da cor.

16 Manchas no espectrograma - destacadas por bolinhas vermelhas, reflexo das frequências de um som complexo, fruto dos dois principais ressoadores do aparelho vocal, a faringe (primeiro formante) e a boca (segundo formante) -, características dos sons vocálicos. 
Linha D'Água (Online), São Paulo, v. 28, n. 1, p. 173-192, jun. 2015

Para estudar com detalhe o enunciado inteiro, em primeiro lugar, com o mesmo arquivo anterior já gravado e registrado no Objects, clicamos novamente em Annotate, logo a seguir, em To Textgride, substituindo as palavras Mary John bell por som sílaba palavra; o sistema gera um novo arquivo; pintamo-lo junto com o original e clicamos em View ĖEdit para visualizá-lo; optamos por dividir o enunciado em três partes, usando o zoom (situado dentro de View, escolhendo novamente zoom to selection)).

Considerações sobre a primeira parte do enunciado (Os vizinhos jogam peteca lá fora), registrada na imagem 5:

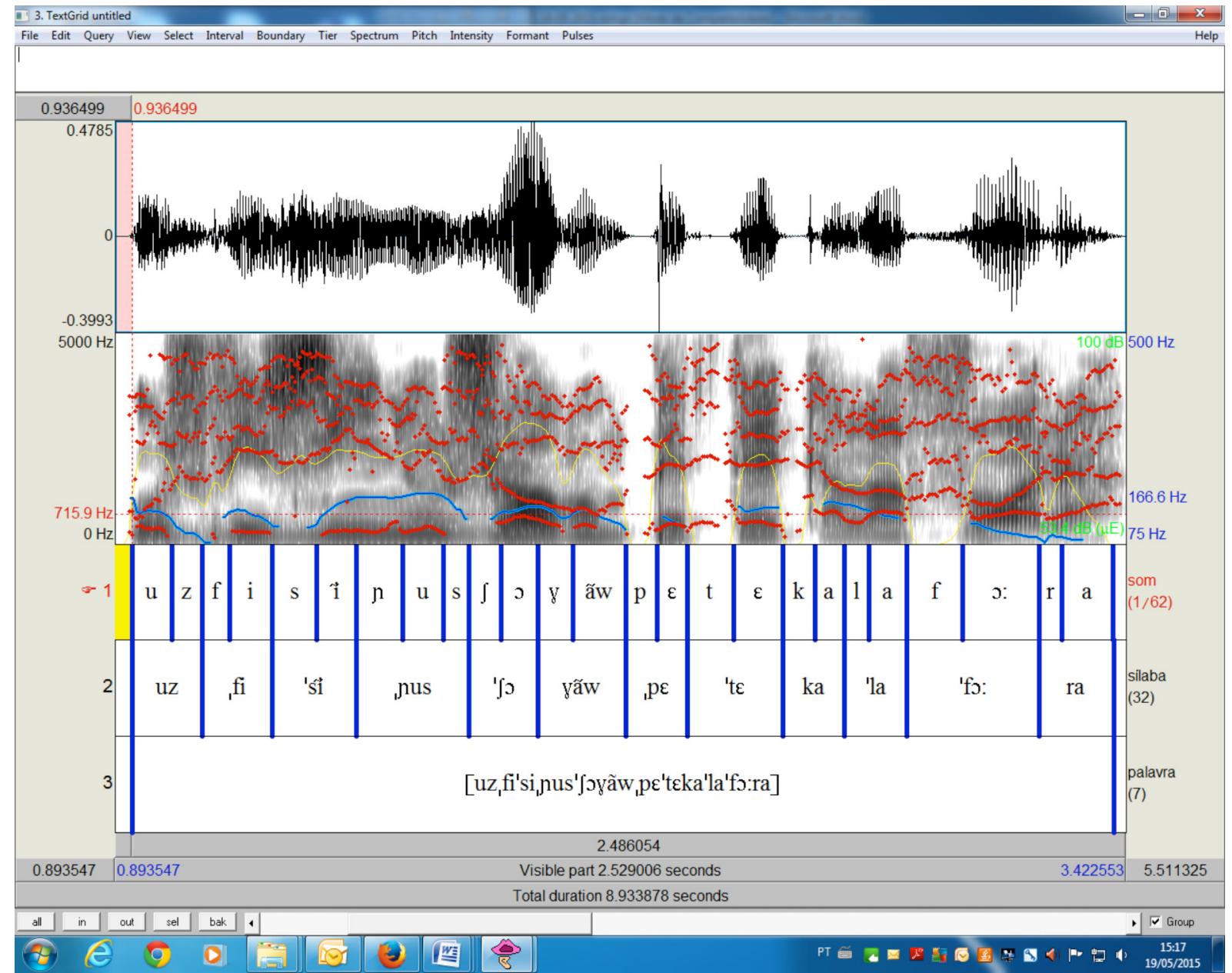

Imagem 5

MASIP, V. Fonética e fonologia portuguesas... 
» quanto ao tom (linha azul, na parte inferior do espectrograma, medida em hertz ${ }^{17}$ ): percebemos que o contorno é interrompido em diversos momentos, devido a que os sons $\operatorname{surdos}^{18}$ não registram a frequência fundamental ${ }^{19}$, base do tom;

" quanto à intensidade (linha amarela/verdosa, na parte superior do espectrograma, medida em decibéis $\left.{ }^{20}\right)$ : percebemos que diversas sílabas tônicas aparecem em destaque ( $\int$, t $\varepsilon$ la fo, acentos primários), mas também, neste enunciado, uma sílaba, átona sob uma perspectiva fonológica, é destacada (pe, acento secundário);

» quanto aos formantes (bolinhas vermelhas): caracterizam claramente a emissão vocálica;

» quanto ao espectrograma (manchas escuras, misturadas com espaços em branco): chamam a atenção, em primeiro lugar, os silêncios que caracterizam os sons oclusivos ${ }^{21}$ surdos [p] [t] [k], devido ao fechamento dos lábios, lábios/dentes e dorso da língua/palato respectivamente; em segundo lugar, a irregularidade das ondas dos sons fricativos ${ }^{22}$ surdos [f] [s] [S] e $\operatorname{sonoros}^{23}$ [z], por causa do atrito ar/esmalte dentário; em terceiro lugar, a pouca densidade dos sons nasais [ãw] [n] devido à fuga do ar pelas narinas e, finalmente, a aparência vocálica dos sons [1] [r], que apresentam uma estrutura formântica definida, proveniente do mínimo contato alveolar ${ }^{24}$, que os torna semelhantes a emissões;

» quanto à duração, percebemos que a sílaba tônica, situada antes de pausa, ['fo:] tem maior duração que as demais, por isso a marcamos com dois pontos;

» percebe-se que o falante é estrangeiro porque produz

17 Ciclos por segundo; parâmetro físico para medição de frequências.

18 Articulados sem vibração das cordas vocais.

19 Primeira onda sinusoidal periódica.

20 Unidade logarítmica que indica a proporção de uma quantidade física (geralmente energia ou intensidade) em relação a um nível de referência especificado ou implícito. Uma relação em decibéis é igual a dez vezes o logaritmo de base 10 da razão entre duas quantidades de energia. Um decibel é um décimo de um bel, uma unidade raramente usada.

21 Que fecham a passagem de ar.

22 Produzidos mediante fricção ou atrito.

23 Sons emitidos ou articulados mediante a vibração das cordas vocais.

24 Face interior dos dentes, contígua à gengiva. 
Linha D'Água (Online), São Paulo, v. 28, n. 1, p. 173-192, jun. 2015

» os sons [v] e [z] de [vi'zinuz] e [3] de ['zogãw] de modo desvozeado, ou seja, sem sonoridade, como [f], [s] e [S] respectivamente, o que se comprova pela ausência da frequência fundamental;

» o som oclusivo [g] de ['zogãw] como aproximante ${ }^{25}[\gamma]$, o que se comprova pela ausência de silêncio no espectrograma.

Considerações sobre a segunda parte do enunciado (na bodega de Mané), registrada na imagem 6:

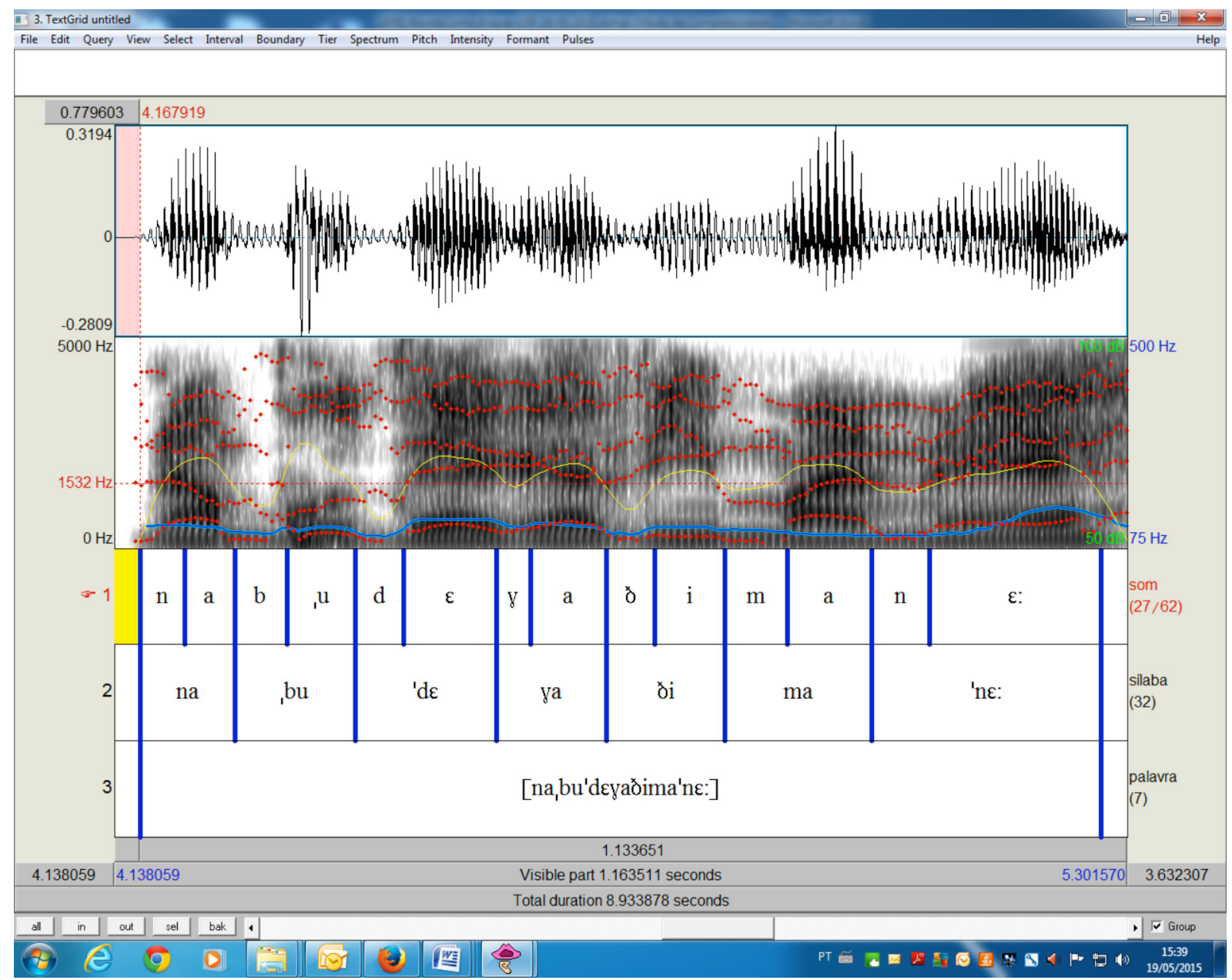

Imagem 6

Além das observações já feitas sobre tom, intensidade e estrutura formântica, que se podem aplicar a esta segunda parte, fica clara a diferença entre os sons

25 Que não provoca oclusão.

MASIP, V. Fonética e fonologia portuguesas... 
Linha D'Água (Online), São Paulo, v. 28, n. 1, p. 173-192, jun. 2015

oclusivos surdos [p] [t] [k], visualizados na primeira parte, e os oclusivos sonoros [b] [d], que apresentam formantes de baixa intensidade no pé do espectrograma. Nota-se que o falante é estrangeiro porque produz:

" [,bu'deva], em lugar de [,bu'dega]: traços aproximantes, velares, sonoros presentes em [8], em lugar dos oclusivos velares sonoros de [g], revelados pela ausência de silêncio;

" [ði], em lugar de [di]: traços aproximantes, linguodentais, sonoros presentes em [ð], em lugar dos oclusivos, linguodentais, sonoros de [d], revelados pela ausência de silêncio;

» o [a] de [ma'ne:] de modo pouco nasalizado, o que se nota pela sua excessiva densidade ${ }^{26}$ ao não existir fuga da corrente de ar pelas narinas;

" quanto à duração, percebemos também que a sílaba tônica, situada antes de pausa, ['nع:] tem maior duração que as demais, por isso a marcamos com dois pontos.

Considerações sobre a terceira parte do enunciado (imagem 7):

26 Concentração de energia em determinada zona. 
Linha D'Água (Online), São Paulo, v. 28, n. 1, p. 173-192, jun. 2015

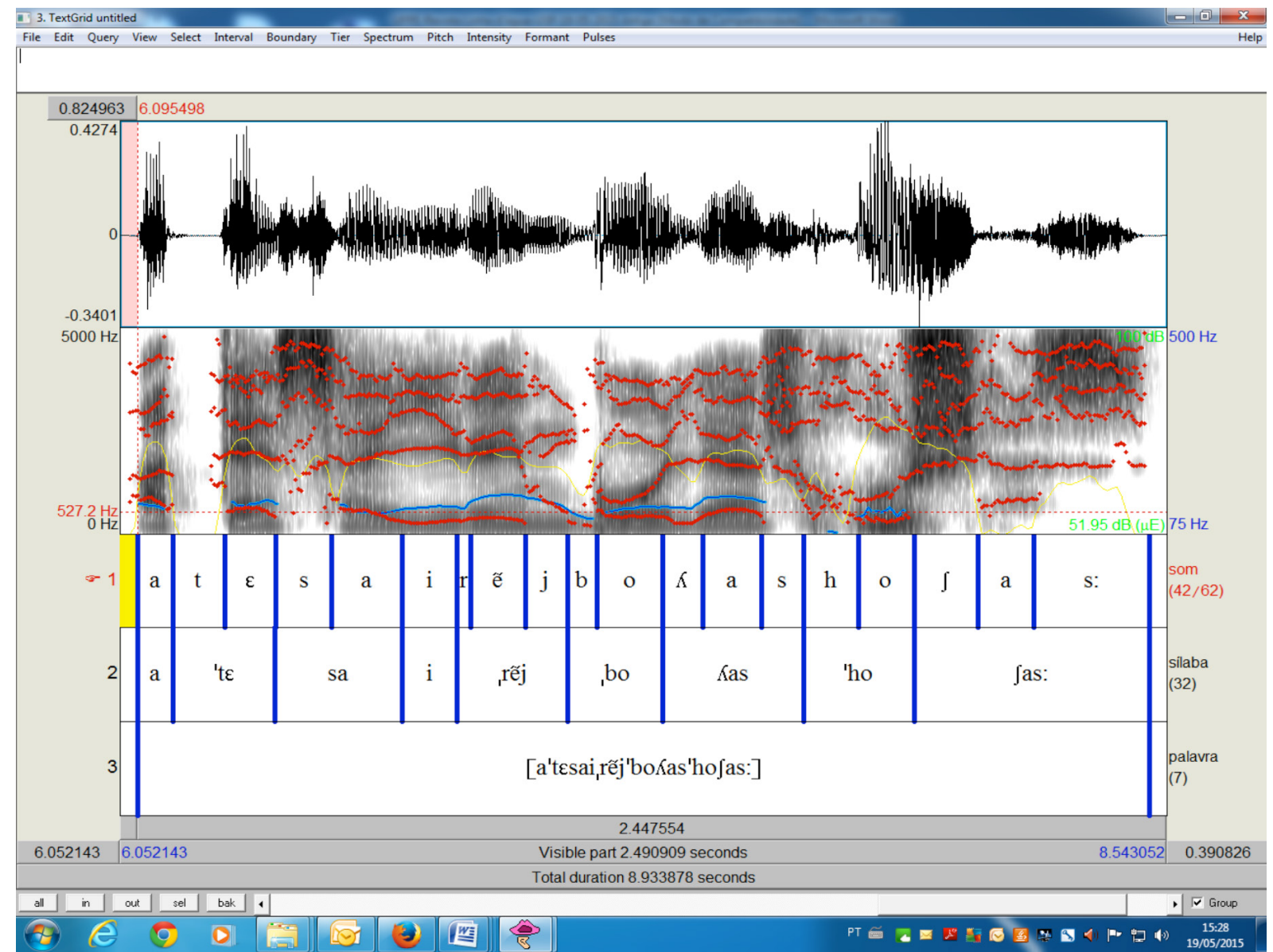

Imagem 7

» aparece clara a diferença entre o som oclusivo surdo [t] de [a'tz] e o oclusivo sonoro [b] de ['boKas], pois o primeiro apresenta uma interrupção total, enquanto o segundo detém formantes de baixa intensidade no pé do espectrograma;

" chama a atenção a total irregularidade das ondas sonoras e a grande densidade do som [s], presente em [sa'irẽj], ['boKas], ['hoJas];

" confirma-se a ausência da frequência fundamental nos sons surdos $[\mathrm{t}][\mathrm{s}]$ [h]; no caso da vogal [a] de ['hofas], a ausência da marca de tom se deve à sua débil emissão;

" a nasalidade do ditongo decrescente [ẽj] de [sa'irẽj] aparece bem, pois a vogal nuclear perde densidade, devido ao desvio da corrente de ar pelas narinas;

» o [i] de [sairẽj], tônico do ponto de visto fonológico, é emitido de modo átono, como se comprova pela curva da intensidade, carente de relevância; note-se que a intensidade de [ẽ] supera à de [i]. 
Linha D'Água (Online), São Paulo, v. 28, n. 1, p. 173-192, jun. 2015

Alguns detalhes denunciam a origem forânea do informante: a manutenção do som [s] em ['boKas'hofas] bolhas roxas, que um recifense produziria [S] ['boKa]'ho Jas] bolhas roxas, ao estar situado imediatamente antes de um som surdo ou em fim de palavra; a realização de sílabas átonas como tônicas mediante acentos secundários [sai, rẽj], em lugar de [sa'irẽj] saírem e o prolongamento da sílaba átona final de palavra ['hofas:] roxas, antes de pausa, realização pouco comum entre os nordestinos, que costumam prolongar a tônica antes de pausa ['ho:[as] roxas.

Para percebermos os contrastes entre o perfil teórico da língua portuguesa, a realização fonética produzida por um falante de português, tomado como modelo, usuário da variante nordestina recifens $\mathrm{e}^{27}$, e o enunciado do informante estrangeiro pesquisado, apresentamos as três transcrições do enunciado, em sequência, precedidas pelo registro ortográfico. Como dizemos inicialmente, a fala escolhida contém todos os fonemas portugueses; a transcrição fonética-modelo substitui o fonema $/ \mathrm{R} /$ pelo alofone $\mathrm{e}^{28}[\mathrm{~h}]$ e o informante pesquisado produz $/ \mathrm{v} /$ como $[\mathrm{f}], / 3 /$ como $\left[\int\right], / g /$ como $[\mathrm{\gamma}] \mathrm{e} / \mathrm{R} / \mathrm{como}[\mathrm{h}]$.

Transcrição ortográfica:

Os vizinhos jogam peteca lá fora, na bodega de Mané, até sairem bolhas roxas.

Transcrição fonológica (arquifonemas ${ }^{29}$, em letras maiúsculas):

27 O fonetista Antonio Quilis (1979; 1988), em dois artigos publicados pela Revista de Filología Española, ao longo dos quais compara os sistemas fonológicos espanhol e português e a entonação de ambas as línguas, assinala algumas características da variante nordestina, da qual faz parte o dialeto recifense: produção do som fricativo alveolar surdo [s] como fricativo palatal surdo [S] em fim de palavra, precedido, em muitos contextos, de semivogal ['voj::] voz, ou imediatamente antes de som consonantal surdo ['vojf'pu:ra] voz pura; articulação do som vibrante velar sonoro [R] como fricativo velar surdo [h] em qualquer contexto [a'hoj $\int_{1}$ hefo'ga:du] arroz refogado; atribuição de acento secundário a sílabas átonas, especialmente as pré-tônicas que iniciam palavra, realizando a vogal anterior médio/alta palatal [e] como anterior médio/ baixa palatal $[\varepsilon]$ [pehnã'bu:ku] Pernambuco e a posterior médio/alta velar [o] como posterior, médio/baixa velar [0] [1sofri'mẽ:tu; severa nasalização vocálica, tanto em sílaba livre, seguida de som consonantal nasal [m] [n] [n] ['kã:ma] ['kã:na] ['ũ:na] cama, cana, unha, quanto travada por [m] [n] ['kã:pu] ['kã:tu] campo, canto; destacada curva entonacional e, finalmente, prolongamento da sílaba tônica antes de pausa.

28 Variante de um fonema; som efetivamente realizado.

29 Conjuntos de traços distintivos, comuns a dois ou mais fonemas; caracterizam alguns sons consonantais que fecham sílaba ou palavra, responsáveis pela maioria das variantes dialetais. 
Linha D'Água (Online), São Paulo, v. 28, n. 1, p. 173-192, jun. 2015

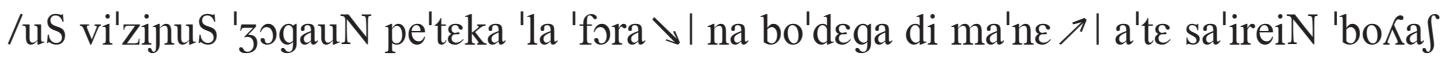

$$
\text { 'RoSaS \III/ }
$$

Transcrição fonética de um falante de português, tomado como modelo, usuário da variante nordestina recifense

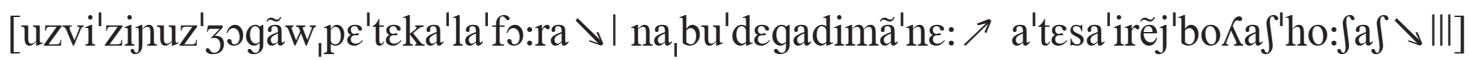

Transcrição fonética do informante estrangeiro pesquisado

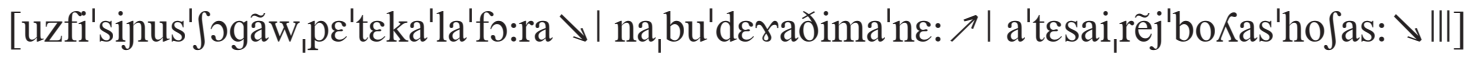

Os desvios (a respeito da variante recifense) do informante estrangeiro aparecem destacados a acima.

\section{Conclusões}

Até vinte anos atrás, era muito complexo e dispendioso trabalhar com laboratórios fonéticos (Cf. QUILIS, 1991; 1993), pois havia que dispor de aparelhagens importadas - as melhores eram fabricadas pela Kay Elemetrics - computadores especialmente projetados ad hoc, cabines para gravação. $\mathrm{Na}$ atualidade, qualquer computador pessoal desempenha a tarefa satisfatoriamente, de modo que o estudo e a análise do som se tornaram tarefas acessíveis à maioria; assim, é chegado o momento de divulgar seu uso, tanto em universidades quanto em escolas de ensino fundamental e médio, com o objetivo de detectar, descrever e diagnosticar problemas linguísticos, na área da alfabetização ou da formalização do português e de línguas indígenas e no ensino de línguas estrangeiras. Ao longo do presente artigo, tentamos expor um modelo de abordagem, em duas fases, que poderá servir de ponto de partida para futuros aprofundamentos.

\section{Referências}

CHOMSKY, Noam. \& HALLE, Morris. The Sound Pattern of English. New York: Harper \& Row. 1968.

CUNHA, Celso; CINTRA, Lindley. Nova gramática do português contemporâneo. Rio de Janeiro: Nova Fronteira, 1985. 
Linha D'Água (Online), São Paulo, v. 28, n. 1, p. 173-192, jun. 2015

JAKOBSON, Roman e HALLE, Morris. Fundamentals of language. New York: Mouton Publishers. 1980.

MARTINET, André. La lingüistica sincrónica. Madrid: Gredos, 1978.

MASIP, Vicente. Fonologia, fonética e ortografia portuguesas. Rio de Janeiro: GEN/LTC. 2014.

MATTOSO CÂMARA, Junior. Para o estudo da fonêmica portuguesa. Rio de Janeiro: Padrão, 1977.

MONTES DE OCA, Domingo Román. Manual para análisis fonético acústico. Santiago de Chile: PFIFFER. 2011.

MORRIS, Charles. "Fundamentos da teoria dos signos". In Problemas e métodos da semiologia. Lisboa: Edições 70, p. 31-41. 1966.

QUILIS, Antonio. El comentario fonológico y fonético de textos (teoría y práctica). Madrid: Arco/ Libros. 1991.

. Tratado de fonología y fonética españolas. Madrid: Gredos, 1993.

"Estudio comparativo entre la entonación portuguesa (de Brasil) y la española". In Revista de Filología Española. Madrid, n. 68: 33-65. 1988.

. “Comparación de los sistemas fonológicos del español y del portugués”. In Revista Española de Lingüística. Madrid, n. de enero-junio: 1-22. 1979.

SAUSSURE, Ferdinand de. Curso de Linguística Geral. São Paulo: Cultrix. 1989.

TROUBETZKOY, Nikolay Sergeyevich. Principes de Phonologie. Paris: Ed. Klincksieck. 1976.

Recebido: 02/01/2015.

Aprovado: 29/05/2015. 